\title{
MicroRNA-202 prevents precocious spermatogonial differentiation and meiotic initiation during mouse spermatogenesis
}

Jian Chen ${ }^{1}$, Chenxu Gao ${ }^{1,2}$, Xiwen Lin ${ }^{1}$, Yan Ning ${ }^{1,2}$, Wei He ${ }^{1,2}$, Chunwei Zheng ${ }^{1}$, Daoqin Zhang ${ }^{1}$, Lin Yan ${ }^{1,3}$, Binjie Jiang ${ }^{1}$, Yuting Zhao ${ }^{1,2}$, Md Alim Hossen ${ }^{1,2}$, and Chunsheng $\operatorname{Han}^{1,2,4, *}$

${ }^{1}$ State Key Laboratory of Stem Cell and Reproductive Biology, Institute of Zoology, Chinese Academy of Sciences, Beijing 100101, China

${ }^{2}$ University of Chinese Academy of Sciences, Savaid Medical School, Beijing 100049, China

${ }^{3}$ Institutes of Physical Science and Information Technology, Anhui University, Hefei 230601, Anhui, China

${ }^{4}$ Institute for Stem Cell and Regeneration, Chinese Academy of Sciences, Beijing 100101, China

*To whom correspondence may be addressed. Email: hancs@ioz.ac.cn.

\section{Running Title}

$m i R-202$ regulates entry into meiosis in males

\section{Keywords}

$m i R-202$, spermatogenesis, spermatogonial differentiation, meiotic initiation, DMRT6, STRA8 


\title{
Summary statement
}

A single miRNA, $m i R-202$, prevents precocious differentiation and meiotic initiation during spermatogenesis. $m i R-202$, DMRT6 and STRA8 act together as a novel module in the regulatory network of meiotic initiation.

\begin{abstract}
Spermatogonial differentiation and meiotic initiation during spermatogenesis are tightly regulated by a number of genes including those coding enzymes for miRNA biogenesis. However, whether and how single miRNAs regulate these processes remain unclear. Here, we report that $m i R-202$, a member of the let-7 family, prevents precocious spermatogonial differentiation and meiotic initiation in spermatogenesis by regulating the timely expression of many genes including those for other key regulators. In $m i R-202$ knockout (KO) mice, the undifferentiated spermatogonial pool is reduced, ultimately causing agametic seminiferous tubules. SYCP3, STRA8 and DMRT6 are expressed earlier in KO mice than in wild-type (WT) littermates, and Dmrt6 mRNA is a direct target of miR-202-5p. Moreover, the precocious spermatogonial differentiation and meiotic initiation were also observed in $\mathrm{KO}$ spermatogonial stem cells when cultured and induced in vitro, and could be rescued by the knockdown of Dmrt6. Therefore, we have not only shown that miR-202 is a novel regulator of meiotic initiation but also added a new module to the underlying regulatory network.
\end{abstract}




\section{Introduction}

Spermatogenesis begins with the proliferation and differentiation of spermatogonia and ends with a huge population of spermatozoa. Mouse spermatogonia undergo 8 to 9 consecutive mitotic divisions to generate many subtypes including type A (SG-A), intermediate (SG-I), and type B (SG-B) spermatogonia (de Rooij and Russell, 2000; Griswold, 2016). Consequently, it is estimated one spermatogonial stem cell (SSC) produces about 4096 spermatozoa at the end of spermatogenesis (de Rooij and Russell, 2000). These subtypes can also be roughly divided into undifferentiated ( $\left.\mathrm{SG}_{\text {undiff }}\right)$ and differentiating spermatogonia ( $\mathrm{SG}_{\text {diff). While }} \mathrm{SG}_{\text {undiff }}$ are marked by the expression of PLZF (Buaas et al., 2004; Costoya et al., 2004), $\mathrm{SG}_{\text {diff }}$ are positive for KIT, a well-known marker for transitamplifying cells in some other tissues (Besmer et al., 1993). SSCs are a functionally defined subpopulation of SGundiff without specific markers (La et al., 2018; Yoshida, 2019). The transition from $S G_{\text {undiff }}$ to $S G_{\text {diff }}$ occurs cyclically, resulting in the concurrent presence of several types of cells originated from overlapping cycles to form a fixed number of unique associations (12 in mice) known as seminiferous stages (Russell et al., 1990). Spermatogonial differentiation ends with mitosis-tomeiosis transition, also known as meiotic initiation, which is the hallmark for gametogenesis (de Rooij and Russell, 2000; Griswold, 2016). The disruption of spermatogonial differentiation reduces sperm population (Hobbs et al., 2012; Maezawa et al., 2017). On the other hand, the precocious differentiation/meiosis leads to exhaustion of the spermatogonial pool (Matson et al., 2010).

Spermatogonial development is under the control of both extracellular and intracellular factors. For example, a low level of glial-cell-line-derived neurotrophic factor (GDNF) in $\mathrm{GDNF}^{+/-}$mice was found to result in Sertoli-cell-only seminiferous tubules whereas its overexpression in transgenic mice resulted in an over-proliferation of spermatogonia and testicular tumors (Meng et al., 2000). Retinoic acid (RA) is the key molecule to induce spermatogonial differentiation and meiotic initiation by activating the expression of a large number of genes (Bowles et al., 2006; Koubova et al., 2006; Anderson et al., 2008a; Endo et al., 2015; Wang et al., 2016; Griswold and Hogarth, 2018). The stimulated by retinoic acid gene 8 (Stra8) is a direct target and mediator of RA signaling, and plays an essential role in meiotic initiation in both 
males and females (Oulad-Abdelghani et al., 1996; Anderson et al., 2008a; Griswold and Hogarth, 2018; Ishiguro et al., 2020). STRA8 is also shown to promote spermatogonial differentiation (Endo et al., 2015).

A number of regulators for spermatogonial differentiation and/or meiotic initiation have also been identified, including transcriptional/epigenetic regulating factors such as SOX3 (Raverot et al., 2005), SOHLH1 (Ballow et al., 2006), SOHLH2 (Hao et al., 2008), DMRT1 (Matson et al., 2010), SALL4 (Hobbs et al., 2012), DMRT6 (Zhang et al., 2014), MAX (Suzuki et al., 2016), PRC1 (Maezawa et al., 2017) and MEIOSIN (Ishiguro et al., 2020), RNA binding proteins such as NANOS2 (Suzuki and Saga, 2008), DAZL (Lin et al., 2008), AGO4 (Modzelewski et al., 2012) and BCAS2 (Liu et al., 2017), and ubiquitylation-related protein $\beta-\operatorname{TrCP}$ (Nakagawa et al., 2017). DMRT proteins are transcription factors, and some members have been reported to participate in multiple steps of mammalian spermatogenesis (Zhang and Zarkower, 2017). DMRT1 is required in the establishment and maintenance of SSCs (Zhang et al., 2016), and prevents the precocious activation of the mitosis-meiosis switch (Matson et al., 2010). DMRT6 acts in SGdiff to coordinate an orderly transition from the mitotic program to the meiotic program (Zhang et al., 2014).

MiRNAs are fundamental to the developmental, physiologic, and disease processes of metazoans via direct posttranscriptional repression of mRNA targets (Bartel, 2018). In somatic stem/progenitor cells, miRNA function is intricately regulated to promote and stabilize cell fate determination (Shenoy and Blelloch, 2014). Whereas global miRNA loss resulting from $\mathrm{KO} /$ mutations of key regulators in miRNA biogenesis induces dramatic phenotypic changes in almost all examined tissues, mice with individual miRNA KOs often lack dramatic phenotypic consequences, implying that miRNAs act in a redundant manner (Park et al., 2012; Shenoy and Blelloch, 2014). MiRNAs are in fact believed to be essential for mammalian spermatogenesis based on the infertile phenotypes of gene $\mathrm{KO}$ mice, including KOs of Dicer, Drosha, and $D g c 8$, which encode key regulators of miRNA biogenesis (Hayashi et al., 2008; Maatouk et al., 2008; Korhonen et al., 2011; Romero et al., 2011; Greenlee et al., 2012; Wu et al., 2012; Zimmermann et al., 2014; Modzelewski et al., 2015; Hilz et al., 2016). However, there have been no reports on 
the in vivo functions of single miRNAs in spermatogenesis based on mouse genetic studies.

The intergenic miRNA gene $m i R-202$ belongs to the highly conserved let-7 family (Roush and Slack, 2008) that generates $m i R-202-3 p$ and $m i R-202-5 p$, which are highly expressed in mouse testes. We previously reported that $m i R-202$ played an important role in maintaining the stem cell state of cultured mouse spermatogonia (Chen et al., 2017). In the present study, we investigated the in vivo function of $m i R$ 202 in the spermatogonial differentiation and meiotic initiation by using $\mathrm{KO}$ mice. We found that both spermatogonial differentiation and meiotic initiation occurred precociously upon miR-202 KO. We also identified that SYCP3, STRA8 and DMRT6 were aberrantly and early expressed in the absence of $m i R-202$, and found that DMRT6, whose mRNA was a direct target of $m i R-202-5 p$, mediated the function of $m i R-202$. Our results contribute to our understanding of how a single miRNA safeguards the spermatogonial differentiation and meiotic initiation.

\section{Results}

\section{MiR-202 knockout reduces the undifferentiated spermatogonial pool}

The $m i R-202 \mathrm{KO}$ mice were produced by CRISPR-Cas9 technology, as described in detail in another study (Chen et al., 2021 preprint). No apparent defects were observed in the seminiferous tubules of KO mice at 2 months of age (Fig. S1A), but loss of germ cells became progressively more severe in an age-dependent manner (Fig. 1A and S1A). At 12 months of age, some KO seminiferous tubules were agametic, containing only the somatic Sertoli cells (Fig. 1B and S1B). This phenotype was reminiscent of that of the KO mice of PLZF, a transcriptional factor expressed in $\mathrm{SG}_{\text {undiff. }} \mathrm{PLZF}$ is required for the maintenance of the SSC pool, as its $\mathrm{KO}$ mice are depleted of germ cells in an age-dependent manner (Buaas et al., 2004; Costoya et al., 2004). Therefore, we examined the expression changes of PLZF in miR-202 KO mice

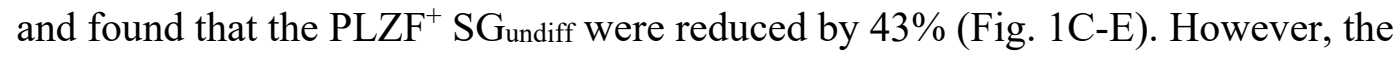
numbers of differentiating spermatogonia represented by the $\mathrm{KIT}^{+}$cells inside the tubules were similar in the KO and WT mice (Fig. S2A-C), showing that the ability of spermatogonial differentiation was not disturbed in $\mathrm{KO}$ mice. These results indicated that $m i R-202 \mathrm{KO}$ reduced the pool of $\mathrm{SG}_{\text {undiff. }}$ 


\section{MiR-202 knockout induces differentiation- and meiosis-related gene transcription in spermatogonia}

To examine whether reduction in $\mathrm{KO}_{\mathrm{SG}}$ undiff would be caused by premature differentiation/meiosis in vivo, we next executed RNA-seq analysis on SG-A (Fig. S3A-B and Table S1), and identified 146 upregulated and 721 downregulated genes resulting from miR-202 KO (Fig. 1F, Table S1). The upregulated genes were enriched with GO terms including spermatogenesis, sperm motility, cell differentiation, spermatid development and binding of sperm to zona pellucida (Fig. 1G, Table S1). Gene-set enrichment analysis (GSEA) also revealed that genes involved in the GO term of sperm motility were significantly upregulated in KO SG-A (Fig. S3C). Moreover, using qRT-qPCR we validated the downregulation of genes involved in maintaining the undifferentiated spermatogonia (including Gfral and Oct4), and the upregulation of genes promoting spermatogonial differentiation and meiotic initiation/progression (such as Sohlh1, Sohlh2, Kit, Stra8, Dazl, Spo 11, Sycp3, Sycp1, Dmcl, Rad51, and Mlhl) in KO SG-A (Fig. 1H) (La et al., 2018). These results suggested that the reduction of $\mathrm{SG}_{\text {undiff }}$ pool was caused by precocious spermatogonial differentiation and meiotic initiation.

\section{MiR-202 knockout results in precocious spermatogonial differentiation and meiotic initiation}

We then examined the timing of meiotic initiation by using pre-pubertal mice, in which the first wave of spermatogenesis occurs in a synchronized manner (de Rooij and Russell, 2000). In WT mice at postnatal day 9 (P9), only 20\% of the tubules contained cells of $\mathrm{SYCP}^{+}$, which marked meiotic spermatocytes (Mahadevaiah et al., 2001 ), whereas in the KO mice, about $72 \%$ of tubules contained positive cells (Fig. 2A-B and S4A). SYCP3 and $\gamma \mathrm{H} 2 \mathrm{AX}$ co-staining of chromosomal spreads (Mahadevaiah et al., 2001) from mice at P9 showed that the most advanced spermatogenic cells in the WT mice were leptotene spermatocytes, whereas $23 \%$ of spermatocytes were zygotene spermatocytes in the KO mice at this time (Fig. 2C-D). These results supported our hypothesis that meiosis was precociously initiated.

To further verify the observations in KOs, we examined the expression pattern of STRA8 as it is a key factor promoting spermatogonial differentiation and meiotic 
initiation (Anderson et al., 2008b; Mark et al., 2008; Endo et al., 2015; Ishiguro et al., 2020). Compared with the WT mice, testis sections from KO mice at P9 contained more STRA $8^{+}$tubules ( 2.2-fold increase) (Fig. 2E-F and S4B). The tubules with robust STRA8 expression in adult KO mice were also significantly increased compared with the WT littermates (25\% vs. 17\%; Fig. 2G-H). The upregulation of STRA8 was confirmed through western blot analyses, which displayed 2- and 1.6fold increases in P9 and adult testes, respectively (Fig. 2I-L and S9A-B).

We next wondered how the increased STRA8 level arose by co-immunostaining for STRA8 and PLZF. STRA8 is expressed at low levels in spermatogonia and at greatly elevated levels in preleptotene spermatocytes (pre-lep) where mitosis-meiosis transition occurs (Zhou et al., 2008). STRA8 expression overlaps with PLZF in stages VII-VIII, and is limited to PLZF-low and -negative spermatogonia thereafter in stages IX-X (Endo et al., 2015). We found that more PLZF ${ }^{+}$cells became STRA $8^{+}$cells in KO than in WT at P9 and 4 months of age (Fig. 3A-D). Moreover, in adult mice, STRA8 expression also overlapped with PLZF in stages I-VI in KOs, showing the widespread and early presence of STRA8 independent of the seminiferous epithelial cycle (Fig. 3C, E). Taken together, the loss of $m i R-202$ in SGundiff caused precocious spermatogonial differentiation and meiotic initiation.

\section{DMRT6 expression is pre-activated in the absence of $m i R-202$}

We subsequently wondered how $m i R-202$ mediated the precocious meiotic initiation. As Stra 8 mRNA is not a predicted $m i R-202$ target (Paraskevopoulou et al., 2013; Agarwal et al., 2015), we focused on Dmrt6 because: 1) Dmrt6 plays a crucial role in the mitosis/meiosis switch (Zhang et al., 2014); 2) its 3' UTR contains an miR202-5p-binding site (Paraskevopoulou et al., 2013); and 3) its expression was upregulated in $m i R-202$ KO SG-A (Fig. 1F, H). Similar to what was observed for STRA8, the KO testes contained more DMRT6 ${ }^{+}$tubules ( $\sim$ a 2.6-fold increase) relative to the WT tubules at P9 (Fig. 4A-B and S4C). The adult KO mice also contained more DMRT6 ${ }^{+}$tubules than the WT (75\% vs. $68 \%$; Fig. 4C-D), and the upregulation of DMRT6 was also confirmed through western blot analyses in P9 and adult testes (Fig. 2I-L and S9A-B). MiR-202-5p was one of the five most abundant miRNAs in SG-A ( $7 \%$ of total reads, Fig. $4 \mathrm{E})$, according to our RNA sequencing 
data (Chen et al., 2017). Dual luciferase assay revealed that the 3' UTR of Dmrt6 mRNA that contained the predicted target site was actually targeted by the miR-202$5 p$ mimic, and as a negative control, the mutated target sequence was not targeted by $m i R-202-5 p$, further indicating that Dmrt6 was a direct target of miR-202-5p (Fig. 4F). As miR-202 mutants mostly phenocopied mice lacking DMRT1, which was reported to prevent the precocious mitosis/meiosis switch and was expressed in SG and Sertoli cells (Matson et al., 2010), we examined the DMRT1 expression pattern in our KO mice, and found no obvious differences between WT and KO mice (Fig. S5A-B).

To distinguish whether DMRT6 was actually pre-activated in SGundiff, we compared the expression pattern of DMRT6 with that of PLZF in P9 and adult mice

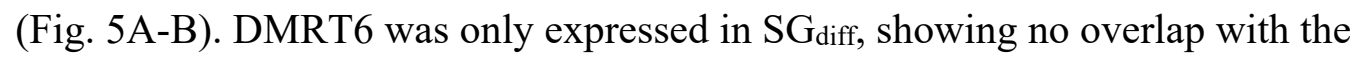
SGundiff marker PLZF (Zhang et al., 2014), and we indeed observed that DMRT6 and PLZF did not co-localize in WT mice (Fig. 5A-B). However, in KOs the DMRT6 and PLZF partially co-localized, indicating that DMRT6 started to be expressed in cells as early as SGundiff (Fig. 5A-B). We also wished to ascertain when DMRT6 would end its expression using co-immunostaining for both DMRT6 and SYCP3 (Fig. S6A-B).

DMRT6 and SYCP3 staining was mutually exclusive in juvenile and adult WT mice, whereas a small number of cells were double-positive in KOs (Fig. S6A-B). In KO adult mice, DMRT6 expression overlapped with SYCP3 in stages VII-VIII, specifically in pre-lep (Fig. S6B). These results indicated that in the absence of $m i R$ -

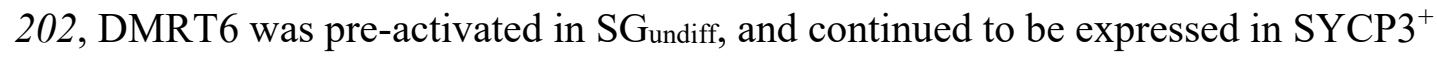
preleptonema. Such an extended expression window may contribute to premature spermatogonial differentiation and meiotic initiation.

\section{Loss of $m i R-202$ primes cultured undifferentiated spermatogonia for spermatogonial differentiation and meiotic initiation}

To further test our hypothesis that the miR-202/DMRT6 axis regulates the initiation of meiosis, we used SSC lines established in in another study (Chen et al., 2021 preprint). The establishment rate of KOs was significantly lower than that of the WT mice (3/7 vs. 11/11; Chi-squared test, $\mathrm{p}<0.005)$. The cells of these SSCs were more appropriately named $\mathrm{SG}_{\text {undiff }}$ because only a small fraction were bona-fide SSCs based upon transplantation assays (Kanatsu-Shinohara et al., 2003; Kubota et al., 
2004). Using these cell lines, we first assessed proliferation, and found that $\mathrm{KO}$ SGundiff were more mitotically active than WT SGundiff based on cell counting and BrdU-incorporation assays (Fig. 6A, S7A-B). However, KO SGundiff also exhibited a higher apoptotic rate, as revealed by TUNEL assays (Fig. 6B, S7C). When we compared the stem cell activity of the WT and $\mathrm{KO} \mathrm{SG}_{\text {undiff }}$ by transplantation assays (Fig. 6C), we found that $\mathrm{KO} \mathrm{SG}_{\text {undiff }}$ exhibited $25 \%$ lower stem cell activity than WT (Fig. 6D), consistent with our previous report (Chen et al., 2017). These results indicated that $m i R$-202 facilitated the maintenance of a more stem cell-like state of $\mathrm{SG}_{\text {undiff that }}$ possessed lower mitotic and apoptotic rates and higher stem cell activity.

We next used an in vitro meiosis-initiation model to further investigate the mechanisms of $m i R-202$ function. Since $\mathrm{SG}_{\text {undiff }}$ cultures can be induced to initiate meiosis when they are plated on a neonatal Sertoli feeder layer (Wang et al., 2016), We monitored the differentiation and meiotic initiation by examining the expression of KIT and SYCP3 (Fig. 6E, S7D). One day after induction, we found that $18 \%$ of the KO cells started to expresses KIT, whereas only 7\% WT cells did so. On day 2 of induction, more KO cells than WT cells began to express SYCP3 (28\% vs. 12\%; Fig. $6 \mathrm{E}, \mathrm{S} 7 \mathrm{D})$. We further conducted co-staining of SYCP3 and $\gamma \mathrm{H} 2 \mathrm{AX}$ on chromosome spreads to examine the types of $\mathrm{WT}$ and $\mathrm{KO} \mathrm{SYCP} 3^{+}$cells that were generated 6 days after induction, and found that the most advanced spermatogenic cells in $\mathrm{KO}$ were zygotene spermatocytes, in contrast to leptotene spermatocytes in WT (Fig. 6F). These in vitro results again indicated that $\mathrm{KO} \mathrm{SG}_{\text {undiff }}$ can be induced to initiate differentiation and meiosis more readily, and that $m i R-202$ deletion predisposed SGundiff to a differentiation- and meiosis-primed state.

\section{MiR-202 function in meiotic initiation is mediated by Dmrt6}

When we examined whether STRA8 and DMRT6 were pre-activated in KO $\mathrm{SG}_{\text {undiff which were PLZF }}$, we indeed detected both STRA8 and DMRT6 in KOs but not in WT, consistent with our previous results (Fig. 6G, S7E). We further tested whether the precocious meiotic initiation of $m i R-202 \mathrm{KO} \mathrm{SG}$ undiff in vitro could be rescued by $m i R-202-5 p$ mimic or by the knockdown of Dmrt6 mRNA. We selected $D n m t 3 b$ (which is involved in DNA methylation) as a potential negative control based on that: 1) Dnmt3b mRNA was upregulated in KO SG-A (Fig. 1H, Table S1); 2) 
Dnmt $3 b$ was a direct target of $m i R-202-3 p$ using dual luciferase assays (Fig. S8A) (Agarwal et al., 2015); and 3) Dnmt3b conditional KO in germ cells manifested no phenotypic abnormality in spermatogenesis (Kaneda et al., 2004). SGundiff cultures were pretreated with miR-202-5p mimic or with siRNAs targeting Dmrt6 and Dnmt3b (Fig. S8B) before induction was conducted. On day 2 of induction, about $27 \%$ of the $\mathrm{KO}$ cells pretreated with control mimic and siRNA were $\mathrm{SYCP}^{+}$, which was similar to the percentage without pretreatment (Fig. 6E, $\mathrm{H}$ and I); this percentage was reduced to $\sim 15 \%$ by pretreatment with the $m i R-202-5 p$ mimic, which approximated the value observed in the WT cells pretreated with a scrambled control (Fig. 6H). Moreover, knockdown of Dmrt6 also reduced the percentages of SYCP $3^{+}$cells significantly, while knockdown of Dnmt3b did not (Fig. 6I). These in vitro results thereby indicated that the function of $m i R-202$ in inhibiting precocious meiotic initiation was mediated by its downstream target, Dmrt6.

\section{Discussion}

Spermatogonial differentiation and meiotic initiation must be precisely regulated to ensure both the productive generation of spermatozoa and the maintenance of the stem cell pool to support the life-long spermatogenesis (Griswold, 2016; Griswold and Hogarth, 2018). However, only a small number of regulators for these two important processes have been identified. In the present study, we found that the KO of $m i R-202$ resulted in precocious spermatogonial differentiation, meiotic initiation, and a reduced $\mathrm{SG}_{\text {undiff }}$ pool. We also demonstrated that loss of $m i R-202$ results in preactivation of STRA8 and DMRT6, two key factors promoting differentiation and meiosis (Oulad-Abdelghani et al., 1996; Anderson et al., 2008a; Zhang et al., 2014; Endo et al., 2015; Griswold and Hogarth, 2018; Ishiguro et al., 2020), in SGundiff, and found that Dmrt6 mRNA was directly targeted by $m i R-202-5 p$. Therefore, a module composed of miR-202, DMRT6 and STRA 8 has been identified in the context of the spermatogonial fate-decision regulatory network (Fig. 7A).

The precocious initiation of spermatogonial differentiation and meiotic initiation in $m i R-202 \mathrm{KO}$ mice are supported by multiple lines of evidences including the premature expression of SYCP3, STRA8, DMRT6, and upregulation of a large number of meiotic and post-meiotic genes. In WT mice, the expression of STRA8 in 
$\mathrm{SG}_{\text {undiff }}$ and pre-lep is restricted in stages VII-VIII of the seminiferous cycle (Endo et al., 2015) while in KO mice, the STRA8 expression was observed in all stages. Moreover, more SGundiff become STRA $8^{+}$in the absence of $m i R-202$ (Fig. 3A-D). DMRT6 is normally expressed in $\mathrm{SG}_{\text {diff }}$ that are negative for PLZF expression (Zhang et al., 2014). However, in the absence of $m i R-202$, the expression of DMRT6 was not only augmented in but also detected as early as in $\mathrm{PLZF}^{+} \mathrm{SG}_{\text {undiff }}$ (Fig. 4A-D, 5A-B). These results suggest that the precise control of spermatogonial differentiation and meiotic initiation was disrupted upon $m i R-202 \mathrm{KO}$ (Fig. 7A).

The regulators that govern the spermatogonial differentiation and/or meiosis identified so far include transcription factors, epigenetic regulators, RNA-binding proteins, and proteins involved in RA pathways. Polycomb repressive complex 1 (PRC1) promotes spermatogonial differentiation by timely activating the expression of germline genes as the gene $\mathrm{KO}$ mice of $R n f 2$, which encodes the catalytic subunit of PRC1, causes severe defects in spermatogonial differentiation (Maezawa et al., 2017). The effect of PRC1 is mediated by SALL4, a transcription factor promoting spermatogonial differentiation by sequestering PLZF from DNA binding (Hobbs et al., 2012; Maezawa et al., 2017). In contrast, MAX, one component of an atypical PRC1 complex (PRC1.6), prevents spermatogonial differentiation and meiotic onset as indicated by the meiosis-like cytological changes induced by its knockdown in cultured germline stem cells (Maeda et al., 2013; Suzuki et al., 2016). Additional meiotic initiation activators include DAZL and MEIOSIN, and suppressors include NANOS2, AGO4 and DMRT1. DAZL is a key regulator to facilitate the meiotic initiation (Lin et al., 2008) and activates the expression of Stra8 by targeting to the 3' UTRs of Stra 8 mRNAs (Li et al., 2019). Interestingly, the expression of Dazl is repressed by NANOS2, which suppresses meiotic initiation, and activated by BCAS2, which promotes the process. Both NANOS2 and BCAS2 are RNA-binding proteins (Suzuki and Saga, 2008; Kato et al., 2016; Liu et al., 2017). AGO4, a small RNA binding protein, prevents precocious meiotic initiation, and its deletion results in loss of many miRNAs, including miR-202 (Modzelewski et al., 2012). It is likely that the function of AGO4 in meiotic initiation is at least partially mediated by $m i R-202$.

MEIOSIN interacts with STRA8 to activate meiotic initiation (Ishiguro et al., 2020).

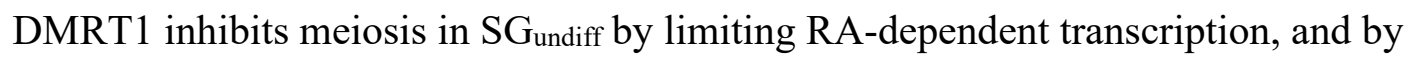


specifically blocking Stra8 transcription at pre-lep (Matson et al., 2010). $\beta$-TrCP, a component of an E3 ubiquitin ligase complex, targets DMRT1 for degradation and thereby activates meiotic initiation (Nakagawa et al., 2017).

MiR-202 KO mice phenocopy the mutants of DMRT1, NANOS2, MAX, and AGO4 in that premature meiotic initiation is observed. However, some differences occur among them. For example, spermatogonial differentiation in DMRT1 KO mice is truncated resulting in SGdiff depletion (Matson et al., 2010), while it does not occur in $m i R-202$ mutants as shown by the unaffected $\mathrm{KIT}^{+} \mathrm{SG}_{\text {diff }}$ (Fig. S3A-C). NANOS2 suppresses meiosis and activates a male-specific genetic program in gonocytes, indicating that NANOS2 plays a key role earlier than miR-202. MAX prevents differentiation/meiosis via interaction with distinct cofactors in cultured cells, and its in vivo function warrants further investigation (Maeda et al., 2013; Suzuki et al., 2016).

Based on our findings and published studies, it can be seen that many regulators cooperate for the fate decision of spermatogonial differentiation and meiotic initiation, and $m i R-202$ and its direct target Dmrt6 as well as Stra8, of which the expression level and timing are also regulated by $m i R-202$, act together as a novel module in this expanding regulatory network which is summarized in Fig. 7B. One interesting research direction in the future is to elucidate how the expression and action of $m i R-202$ are regulated by known or novel players in the network.

\section{Materials and methods}

\section{Mice}

All of the animals used in this study were approved by the Animal Ethics Committee of the Institute of Zoology at the Chinese Academy of Science. All of the procedures were conducted in accordance with institutional guidelines. Animals were specific-pathogen free (SPF). All mice had access to food and water ad libitum, were maintained on a 12:12 hours light-dark artificial lighting cycle, with lights off at 19:00, and were housed in cages at a temperature of $22-24^{\circ} \mathrm{C}$.

The miR-202 KO mice were produced as described in detail in another study (Chen et al., 2021 preprint). All of the mice were maintained on a C57BL/6J;ICR 
mixed background. The deletion of the $m i R-202$ cassette was verified by genomic PCR (Primers are listed in Table S2).

\section{Histological analyses}

Testes dissected from the wildtype and $\mathrm{KO}$ mice immediately after euthanasia were fixed in 4\% paraformaldehyde or Bouin's Solution for up to 24 hours, dehydrated using gradient concentration of ethanol, treated with xylene, and then embedded in paraffin. Five-micrometer-thick sections were cut and mounted on glass slides. After deparaffinization in xylene and re-hydration in gradient concentration of ethanol, the Bouin-fixed testis cross-sections were used for Hemotoxylin and Eosin (HE) staining, and PFA-fixed sections were used for immunohistochemistry (IHC), immunofluorescence (IF) analyses, and TUNEL assays.

\section{Antibodies}

All antibodies used in this study are listed in Table S3. We obtained the antiDMRT6 and anti-DMRT1 antibodies from Prof. David Zarkower in University of Minnesota (Matson et al., 2010; Zhang et al., 2014; Zhang et al., 2016), as generous gifts.

\section{Section immunostaining}

Deparaffinized sections were boiled for $15 \mathrm{~min}$ in a sodium citrate buffer for antigen retrieval. Then, the slides were incubated with primary antibodies overnight at $4^{\circ} \mathrm{C}$ and then incubated with secondary antibodies for two hours at room temperature. For IF, signals were visualized by conjugating fluorophore with the secondary antibodies. For IHC, the sections were stained with a horseradish peroxidase (HRP)conjugated secondary antibody.

\section{Whole-mount immunostaining}

The mouse testes were dissected to remove the tunica albuginea, and seminiferous tubules were untangled. Tubules were fixed in 4\% PFA overnight at $4^{\circ} \mathrm{C}$, permeabilized with $0.1 \%$ Triton $\mathrm{X}-100$ in PBS for four hours at room temperature, and blocked with 5\% BSA in PBS for two hours at room temperature. The tubules were incubated with primary antibodies overnight at $4^{\circ} \mathrm{C}$ and 
subsequently with fluorophore-conjugated secondary antibodies for four hours at room temperature. The nuclei were counterstained with DAPI.

\section{Spermatocyte chromosome spreads}

Chromosome spreads of the testicular samples were performed using the dryingdown technique previously described by Peters et al. (Peters et al., 1997). Briefly, the testes were dissected, and the seminiferous tubules were washed in PBS. Then, tubules were placed in a hypotonic extraction buffer for 30-60 min. Subsequently, the tubules were torn to pieces in $0.1 \mathrm{M}$ sucrose $(\mathrm{pH}$ 8.2) on a clean glass slide and were pipetted repeatedly to make a suspension. The cell suspensions were then dropped on slides containing $1 \%$ PFA and $0.15 \%$ Triton X-100 (pH 9.2). The slides were dried for at least two hours in a closed box with high humidity. Finally, the slides were washed twice with $0.4 \%$ Photo-Flo 200 (Kodak) and dried at room temperature. The dried slides were stored at $-20^{\circ} \mathrm{C}$ for the immunofluorescent staining. Immunolabeled chromosome spread nuclei were imaged on confocal laser scanning microscopes (Leica or Carl Zeiss) using $63 \times$ oil-immersion objective.

\section{Dual luciferase assay}

We used TargetScan or microT-CDS to predict mRNA target sites of $m i R-202$ (Paraskevopoulou et al., 2013; Agarwal et al., 2015). The predicted 3' UTRs for candidate genes were amplified from mouse testis cDNA (Primers are listed in Table S2) and inserted into the pMIR-REPORT Luciferase vector.

Dual luciferase assays were performed following our previous report (Chen et al., 2017). Briefly, the 293FT cells were plated in 96-well plate. About 24 hours later, the $m i R-202$ or scrambled NC mimics of $100 \mathrm{nM}$ were first transfected using the Lipofectamine RNAiMAX Reagent (Invitrogen). Ten hours later, 50 ng of the Firefly Luciferase report plasmids (pMIR-REPORT) and $5 \mathrm{ng}$ of the Renilla Luciferase internal control plasmid (pRT-TK) were co-transfected by the Lipofectamine 2000 Reagent (Invitrogen). Forty-eight hours after plasmid transfection, luciferase activity was examined using the Dual-Luciferase Report Assay System (Promega) on the Synergy4 (Bio-Tek) platform. Data were first normalized to the empty the vector and then to the NC mimic. 


\section{Isolation of type A spermatogonia (SG-A)}

Mice at 6-7 dpp were used for SG-A isolation through the STAPUT method following our previous report (Gan et al., 2013). Mice were sacrificed, and then the testes were removed and decapsulated. The seminiferous tubules were cut into small pieces. The pieces were incubated in DPBS containing Collagenase I (Gibco) and then in Trypsin (Gibco) containing DNase I. The dispersed cells were filtered through a 40- $\mu \mathrm{m}$ cell strainer (BD Falcon). After filtered, the cells were resuspended in $0.5 \mathrm{ml}$ of DMEM containing 0.5\% BSA. Cells were bottom-loaded into a 10-ml syringe, and this was followed by $10 \mathrm{ml}$ of a $2-4 \%$ BSA gradient in DMEM. After two hours of velocity sedimentation at unit gravity, the cell fractions $(0.5 \mathrm{ml} /$ fraction $)$ were collected from the bottom of the syringe at a rate of about $1 \mathrm{ml} / \mathrm{min}$. The cell type and purity in each fraction were assessed using a light microscope based on their diameters and morphological characteristics. Only fractions with a purity $\geq 85 \%$ were pooled together (Fig. S3A-B).

\section{qRT-PCR}

Primers used in qRT-PCR are listed in Table S2. Total RNAs were isolated using Trizol regent (Invitrogen). Total RNAs were reverse-transcribed using High-Capacity cDNA Reverse Transcription Kit (Applied Biosystems) and the reactions were performed using Hieff qPCR SYBR Green Master Mix (Yeasen) in a Roche LightCycler 480 Real-Time PCR system. The data were then analyzed using the comparative $\mathrm{Ct}$ method $(\Delta \mathrm{Ct})$, with $\beta$-actin RNA used as the internal control (Gan et al., 2013).

\section{Cell cultures}

All cells were maintained at $37^{\circ} \mathrm{C}$ under $5 \% \mathrm{CO}_{2}$ and tested negative for mycoplasma contamination. Establishment and maintenance of SSCs (SGundiff in this paper) and Sertoli cells was described in detail in another study (Chen et al., 2021 preprint). The Sertoli cells were treated with mitomycin $\mathrm{C}$ and used for induction of meiotic initiation. The 293FT cell lines were maintained in DMEM medium supplemented with $10 \%$ FBS.

\section{Western blotting}


Cell lysates from mouse testes were prepared by homogenizing small pieces of organs with glass homogenizers in an RIPA buffer (Beyotime) supplemented with Protease Inhibitor Cocktail (Sigma-Aldrich). Cultured SGundiff were directly lysed in RIPA buffer supplemented with Protease Inhibitor Cocktail. Lysates were then centrifuged at 20,000 g for 10 minutes at $4{ }^{\circ} \mathrm{C}$, and supernatants were used for Western blot analyses. Briefly, lysates were run in SDS-PAGE gel and transferred to PVDF membranes. The blots were blocked with 5\% BSA for 2 hours, incubated with primary antibodies overnight at $4^{\circ} \mathrm{C}$ and then incubated with HRP-conjugated secondary antibodies at room temperature for 2 hours. The proteins were detected using SuperSignal West Pico PLUS Chemiluminescent Substrate (Thermo Fisher) on the ChemiDoc $\mathrm{XRS}^{+}$system (Bio-Rad). The band densities were analyzed by ImageJ.

\section{BrdU incorporation assay}

The $\mathrm{SG}_{\text {undiff }}$ were seeded on Laminin-coated glass in a plate and were treated with $10 \mu \mathrm{g} / \mathrm{ml}$ of BrdU for 12 hours. Then, the cells were fixed with $70 \%$ ice-cold ethanol, denatured with $2 \mathrm{M}$ of $\mathrm{HCl}$ and neutralized with $0.1 \mathrm{M}$ of sodium borate $(\mathrm{pH}$ 8.5). Afterward, the cells were analyzed using a standard procedure similar to that used for immunofluorescence.

\section{Transplantation of $\mathbf{S G}_{\text {undiff }}$}

Transplantation of the SGundiff into recipient testes was performed as described previously (Kubota et al., 2004; Wang et al., 2015). Briefly, and $5 \times 10^{4}$ internal control SGundiff labelled by mRuby2 together with $10^{5}$ WT or KO SG undiff labelled by EGFP were mixed and transplanted into each testis of busulfan-pretreated recipient mice. One month later, the colony number was counted and analyzed.

\section{Meiotic initiation induction of $\mathbf{S G}$ undiff}

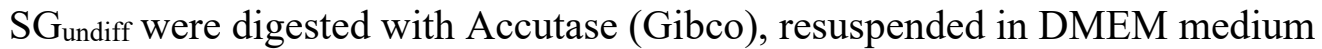
supplemented with 10\% FBS and plated on a dish. After 30 minutes, MEF feeder cells but not $\mathrm{SG}_{\text {undiff }}$ attached to the dish bottom firmly. Floating $\mathrm{SG}_{\text {undiff }}$ were collected and plated to a plate in which mitomycin C-treated Sertoli cells had been prepared beforehand. The induced germ cells were harvested for characterization. For rescue experiments, $100 \mathrm{nM}$ of miRNA mimics or mRNA siRNAs were transfected into 
$\mathrm{SG}_{\text {undiff }}$ using Lipofectamine RNAiMAX reagent ten hours prior to induction (Table S4).

\section{Flow cytometry analysis}

The cultured $\mathrm{SG}_{\text {undiff }}$ were treated with $0.25 \%$ trypsin to dissociate cells. The cells were filtered through a $40-\mu \mathrm{m}$ Nylon Cell Strainer (BD Falcon), fixed in $4 \%$ PFA for 15 minutes, and permeabilized with $0.1 \%$ Triton $\mathrm{X}-100$ for 30 minutes (dispensable for the anti-KIT antibody). After blocked with 5\% BSA in PBS for 30 min, the cells were incubated with primary antibodies at $37^{\circ} \mathrm{C}$ for $1 \mathrm{~h}$ and then incubated with secondary antibodies at $37^{\circ} \mathrm{C}$ for $1 \mathrm{~h}$. The analyses were preformed using a CytoFLEX research cytometer.

\section{RNA sequencing analysis}

Total RNAs were isolated by Trizol. Two biological replicates for SG-A were used. The RNA libraries were constructed using NEBNext Ultra Directional RNA Library Prep Kit for Illumina following manufacturer's recommendations and Oligo (dT) beads (NEB) were used to isolate poly (A) mRNAs. High-throughput sequencing was performed on a Hiseq-PE150 platform.

The correlation coefficients of gene expression levels from biological duplicates were all more than 0.95 . The sequencing reads were mapped to the mouse genome (UCSC, mm9) by TopHat. The mRNA expression level was represented by fragments per kilobase of transcript sequence per millions (FPKM) calculated by Cufflinks. In addition, the differentially expressed genes were identified by Cuffdiff based on the threshold of $p<0.01$ together with fold change $>3 / 2$ or $<2 / 3$. RefSeq mRNAs downloaded from UCSC (mm9) were used as the reference mRNAs.

\section{GO analysis and GSEA analysis}

Gene ontology (GO) analysis was performed using DAVID bioinformatics tools (Huang da et al., 2009) and GO terms with $\mathrm{p}<0.05$ were considered to be significant. GSEA analysis was performed using GSEA v4.0.1 software (Subramanian et al., 2005) with FPKM data.

\section{Statistical analysis}


All experiments reported here were repeated at least three independent times except that RNA-seq for SG-A was performed with two biological samples. All of the values in the figures are shown as mean \pm SEM unless otherwise stated. Excel 2016 or GraphPad Prism 7 was used to perform statistical analyses. For statistical analysis of differences between two groups, two-tailed unpaired Student's t tests were used. For statistical analysis in Fig. 2D, Chi-square test was used. No samples or animals were excluded from analyses. Sample size estimates were not used. Mice analyzed were litter mates and sex-matched whenever possible. Investigators were not blinded to mouse genotypes or cell genotypes during experiments.

In all figures, $*, * *$ and $* * *$ represent $\mathrm{p}<0.05, \mathrm{p}<0.01$, and $\mathrm{p}<0.001$, respectively. NS (not significant) is stated if the comparison is not statistically significant $(\mathrm{p}>0.05)$.

\section{Acknowledgements}

We thank David Zarkower for antibodies. We thank Shiwen Li, Shuguang Duo, Xili Zhu, Xia Yang, Hua Qin and Qing Meng in Institute of Zoology, Chinese Academy of Sciences for their technical assistance. We thank LetPub (www.letpub.com) for its linguistic assistance during the preparation of this manuscript.

\section{Competing interests}

No competing interests declared.

\section{Funding}

This work was supported by the Ministry of Science and Technology of China (2016YFC1000606 to C.H., 2018YFE0201100 to C.H. and 2015CB943002 to C.H.), and the National Natural Science Foundation of China (31771631 to C.H. and 31970795 to C.H.).

\section{Data Availability}

The RNA-seq data set from this study has been submitted to the NCBI Gene Expression Omnibus under the accession number GSE126936. 


\section{Author Contributions}

C.H. supervised the project. C.H. and J.C. conceived and designed the study, analyzed the data and wrote the manuscript. J.C., Y.N., W.H., C.Z., D.Z., L.Y., B.J. and Y.Z. performed the experiments. C.G., X.L., M.A.H. and J.C. conducted the bioinformatics analyses. All authors commented on the manuscript. 


\section{References}

Agarwal, V., Bell, G. W., Nam, J. W. and Bartel, D. P. (2015). Predicting effective microRNA target sites in mammalian mRNAs. Elife 4, e05005.

Anderson, E. L., Baltus, A. E., Roepers-Gajadien, H. L., Hassold, T. J., de Rooij, D. G., van Pelt, A. M. and Page, D. C. (2008a). Stra8 and its inducer, retinoic acid, regulate meiotic initiation in both spermatogenesis and oogenesis in mice. Proc Natl Acad Sci U S A 105(39), 14976-80.

Anderson, E. L., Baltus, A. E., Roepers-Gajadien, H. L., Hassold, T. J., de Rooij, D. G., van Pelt, A. M. and Page, D. C. (2008b). Stra8 and its inducer, retinoic acid, regulate meiotic initiation in both spermatogenesis and oogenesis in mice. Proc Natl Acad Sci U S A 105(39), 14976-80.

Ballow, D., Meistrich, M. L., Matzuk, M. and Rajkovic, A. (2006). Sohlh1 is essential for spermatogonial differentiation. Dev Biol 294(1), 161-7.

Bartel, D. P. (2018). Metazoan MicroRNAs. Cell 173(1), 20-51.

Besmer, P., Manova, K., Duttlinger, R., Huang, E. J., Packer, A., Gyssler, C. and Bachvarova, R. F. (1993). The kit-ligand (steel factor) and its receptor c-kit/W: pleiotropic roles in gametogenesis and melanogenesis. Development. Supplement (Cambridge, Eng), 125-37. Bowles, J., Knight, D., Smith, C., Wilhelm, D., Richman, J., Mamiya, S., Yashiro, K., Chawengsaksophak, K., Wilson, M. J., Rossant, J. et al. (2006). Retinoid signaling determines germ cell fate in mice. Science 312(5773), 596-600.

Buaas, F. W., Kirsh, A. L., Sharma, M., McLean, D. J., Morris, J. L., Griswold, M. D., de Rooij, D. G. and Braun, R. E. (2004). Plzf is required in adult male germ cells for stem cell selfrenewal. Nat Genet 36(6), 647-52.

Chen, J., Cai, T., Zheng, C., Lin, X., Wang, G., Liao, S., Wang, X., Gan, H., Zhang, D., Hu, X. et al. (2017). MicroRNA-202 maintains spermatogonial stem cells by inhibiting cell cycle regulators and RNA binding proteins. Nucleic Acids Res 45(7), 4142-4157.

Chen, Jian, Gao, Chenxu, Zheng, Chunwei, Lin, Xiwen, Ning, Yan, Ma, Longfei, He, Wei, Xie, Dan, Liu, Kui and Han, Chunsheng (2021 preprint). MicroRNA-202 safeguards meiotic progression by preventing premature degradation of REC8 mediated by separase. bioRxiv doi: 10.1101/2021.04.14.439735 April, 2021, pre-print: not peer-reviewed.

Costoya, J. A., Hobbs, R. M., Barna, M., Cattoretti, G., Manova, K., Sukhwani, M., Orwig, K. E., Wolgemuth, D. J. and Pandolfi, P. P. (2004). Essential role of Plzf in maintenance of spermatogonial stem cells. Nat Genet 36(6), 653-9.

de Rooij, D. G. and Russell, L. D. (2000). All you wanted to know about spermatogonia but were afraid to ask. J Androl 21(6), 776-98.

Endo, T., Romer, K. A., Anderson, E. L., Baltus, A. E., de Rooij, D. G. and Page, D. C. (2015). Periodic retinoic acid-STRA8 signaling intersects with periodic germ-cell competencies to regulate spermatogenesis. Proc Natl Acad Sci U S A 112(18), E2347-56.

Gan, H., Wen, L., Liao, S., Lin, X., Ma, T., Liu, J., Song, C. X., Wang, M., He, C., Han, C. et al. (2013). Dynamics of 5-hydroxymethylcytosine during mouse spermatogenesis. Nat Commun 4, 1995.

Greenlee, A. R., Shiao, M. S., Snyder, E., Buaas, F. W., Gu, T., Stearns, T. M., Sharma, M., Murchison, E. P., Puente, G. C. and Braun, R. E. (2012). Deregulated sex chromosome gene expression with male germ cell-specific loss of Dicer1. PLoS One 7(10), e46359.

Griswold, M. D. (2016). Spermatogenesis: The commitment to meiosis. Physiol Rev 96(1), 117.

Griswold, M. D. and Hogarth, C. (2018). Beyond stem cells: Commitment of progenitor cells to meiosis. Stem Cell Research 27, 169-171. 
Hao, J., Yamamoto, M., Richardson, T. E., Chapman, K. M., Denard, B. S., Hammer, R. E., Zhao, G. Q. and Hamra, F. K. (2008). Sohlh2 knockout mice are male-sterile because of degeneration of differentiating type A spermatogonia. Stem Cells 26(6), 1587-97.

Hayashi, K., Chuva de Sousa Lopes, S. M., Kaneda, M., Tang, F., Hajkova, P., Lao, K., O'Carroll, D., Das, P. P., Tarakhovsky, A., Miska, E. A. et al. (2008). MicroRNA biogenesis is required for mouse primordial germ cell development and spermatogenesis. PLoS One 3(3), e1738.

Hilz, S., Modzelewski, A. J., Cohen, P. E. and Grimson, A. (2016). The roles of microRNAs and siRNAs in mammalian spermatogenesis. Development 143(17), 3061-73.

Hobbs, R. M., Fagoonee, S., Papa, A., Webster, K., Altruda, F., Nishinakamura, R., Chai, L. and Pandolfi, P. P. (2012). Functional antagonism between Sall4 and Plzf defines germline progenitors. Cell Stem Cell 10(3), 284-98.

Huang da, W., Sherman, B. T. and Lempicki, R. A. (2009). Systematic and integrative analysis of large gene lists using DAVID bioinformatics resources. Nat Protoc 4(1), 44-57.

Ishiguro, Kei-ichiro, Matsuura, Kumi, Tani, Naoki, Takeda, Naoki, Usuki, Shingo, Yamane, Mariko, Sugimoto, Michihiko, Fujimura, Sayoko, Hosokawa, Mihoko, Chuma, Shinichiro et al. (2020). MEIOSIN Directs the Switch from Mitosis to Meiosis in Mammalian Germ Cells. Dev Cell.

Kanatsu-Shinohara, M., Ogonuki, N., Inoue, K., Miki, H., Ogura, A., Toyokuni, S. and Shinohara, T. (2003). Long-term proliferation in culture and germline transmission of mouse male germline stem cells. Biol Reprod 69(2), 612-6.

Kaneda, M., Okano, M., Hata, K., Sado, T., Tsujimoto, N., Li, E. and Sasaki, H. (2004). Essential role for de novo DNA methyltransferase Dnmt3a in paternal and maternal imprinting. Nature 429(6994), 900-3.

Kato, Y., Katsuki, T., Kokubo, H., Masuda, A. and Saga, Y. (2016). Dazl is a target RNA suppressed by mammalian NANOS2 in sexually differentiating male germ cells. Nat Commun 7(7), 11272.

Korhonen, H. M., Meikar, O., Yadav, R. P., Papaioannou, M. D., Romero, Y., Da Ros, M., Herrera, P. L., Toppari, J., Nef, S. and Kotaja, N. (2011). Dicer is required for haploid male germ cell differentiation in mice. PLoS One 6(9), e24821.

Koubova, J., Menke, D. B., Zhou, Q., Capel, B., Griswold, M. D. and Page, D. C. (2006). Retinoic acid regulates sex-specific timing of meiotic initiation in mice. Proc Natl Acad Sci U S A 103(8), 2474-9.

Kubota, H., Avarbock, M. R. and Brinster, R. L. (2004). Growth factors essential for selfrenewal and expansion of mouse spermatogonial stem cells. Proc Natl Acad Sci U S A 101(47), 16489-94.

La, H. M., Makela, J. A., Chan, A. L., Rossello, F. J., Nefzger, C. M., Legrand, J. M. D., De Seram, M., Polo, J. M. and Hobbs, R. M. (2018). Identification of dynamic undifferentiated cell states within the male germline. Nat Commun 9(1), 2819.

Li, H., Liang, Z., Yang, J., Wang, D., Wang, H., Zhu, M., Geng, B. and Xu, E. Y. (2019). DAZL is a master translational regulator of murine spermatogenesis. Natl Sci Rev 6(3), 455-468.

Lin, Y., Gill, M. E., Koubova, J. and Page, D. C. (2008). Germ cell-intrinsic and -extrinsic factors govern meiotic initiation in mouse embryos. Science 322(5908), 1685-7.

Liu, W., Wang, F., Xu, Q., Shi, J., Zhang, X., Lu, X., Zhao, Z. A., Gao, Z., Ma, H., Duan, E. et al. (2017). BCAS2 is involved in alternative mRNA splicing in spermatogonia and the transition to meiosis. Nat Commun 8, 14182.

Maatouk, D. M., Loveland, K. L., McManus, M. T., Moore, K. and Harfe, B. D. (2008). Dicer1 is required for differentiation of the mouse male germline. Biol Reprod 79(4), 696-703. 
Maeda, I., Okamura, D., Tokitake, Y., Ikeda, M., Kawaguchi, H., Mise, N., Abe, K., Noce, T., Okuda, A. and Matsui, Y. (2013). Max is a repressor of germ cell-related gene expression in mouse embryonic stem cells. Nat Commun 4, 1754.

Maezawa, So, Hasegawa, Kazuteru, Yukawa, Masashi, Sakashita, Akihiko, Alavattam, Kris G., Andreassen, Paul R., Vidal, Miguel, Koseki, Haruhiko, Barski, Artem and Namekawa, Satoshi H. (2017). Polycomb directs timely activation of germline genes in spermatogenesis. Genes \& Development 31(16), 1693-1703.

Mahadevaiah, S. K., Turner, J. M., Baudat, F., Rogakou, E. P., de Boer, P., Blanco-Rodriguez, J., Jasin, M., Keeney, S., Bonner, W. M. and Burgoyne, P. S. (2001). Recombinational DNA double-strand breaks in mice precede synapsis. Nat Genet 27(3), 271-6.

Mark, M., Jacobs, H., Oulad-Abdelghani, M., Dennefeld, C., Feret, B., Vernet, N., Codreanu, C. A., Chambon, P. and Ghyselinck, N. B. (2008). STRA8-deficient spermatocytes initiate, but fail to complete, meiosis and undergo premature chromosome condensation. J Cell Biol 121(Pt 19), 3233-42.

Matson, C. K., Murphy, M. W., Griswold, M. D., Yoshida, S., Bardwell, V. J. and Zarkower, D. (2010). The mammalian doublesex homolog DMRT1 is a transcriptional gatekeeper that controls the mitosis versus meiosis decision in male germ cells. Dev Cell 19(4), 612-24.

Meng, X., Lindahl, M., Hyvonen, M. E., Parvinen, M., de Rooij, D. G., Hess, M. W., Raatikainen-Ahokas, A., Sainio, K., Rauvala, H., Lakso, M. et al. (2000). Regulation of cell fate decision of undifferentiated spermatogonia by GDNF. Science 287(5457), 1489-93.

Modzelewski, A. J., Hilz, S., Crate, E. A., Schweidenback, C. T., Fogarty, E. A., Grenier, J. K., Freire, R., Cohen, P. E. and Grimson, A. (2015). Dgcr8 and Dicer are essential for sex chromosome integrity during meiosis in males. J Cell Sci 128(12), 2314-27.

Modzelewski, A. J., Holmes, R. J., Hilz, S., Grimson, A. and Cohen, P. E. (2012). AGO4 regulates entry into meiosis and influences silencing of sex chromosomes in the male mouse germline. Dev Cell 23(2), 251-64.

Nakagawa, T., Zhang, T., Kushi, R., Nakano, S., Endo, T., Nakagawa, M., Yanagihara, N., Zarkower, D. and Nakayama, K. (2017). Regulation of mitosis-meiosis transition by the ubiquitin ligase beta-TrCP in male germ cells. Development 144(22), 4137-4147.

Oulad-Abdelghani, M., Bouillet, P., Decimo, D., Gansmuller, A., Heyberger, S., Dolle, P., Bronner, S., Lutz, Y. and Chambon, P. (1996). Characterization of a premeiotic germ cellspecific cytoplasmic protein encoded by Stra8, a novel retinoic acid-responsive gene. Journal of Cell Biology 135(2), 469-77.

Paraskevopoulou, M. D., Georgakilas, G., Kostoulas, N., Vlachos, I. S., Vergoulis, T., Reczko, M., Filippidis, C., Dalamagas, T. and Hatzigeorgiou, A. G. (2013). DIANA-microT web server v5.0: service integration into miRNA functional analysis workflows. Nucleic Acids Res $\mathbf{4 1}$ (Web Server issue), W169-73.

Park, C. Y., Jeker, L. T., Carver-Moore, K., Oh, A., Liu, H. J., Cameron, R., Richards, H., Li, Z., Adler, D., Yoshinaga, Y. et al. (2012). A resource for the conditional ablation of microRNAs in the mouse. Cell Rep 1(4), 385-91.

Peters, A. H., Plug, A. W., van Vugt, M. J. and de Boer, P. (1997). A drying-down technique for the spreading of mammalian meiocytes from the male and female germline.

Chromosome Res 5(1), 66-8.

Raverot, G., Weiss, J., Park, S. Y., Hurley, L. and Jameson, J. L. (2005). Sox3 expression in undifferentiated spermatogonia is required for the progression of spermatogenesis. Dev Biol 283(1), 215-25.

Romero, Y., Meikar, O., Papaioannou, M. D., Conne, B., Grey, C., Weier, M., Pralong, F., De Massy, B., Kaessmann, H., Vassalli, J. D. et al. (2011). Dicer1 depletion in male germ cells leads to infertility due to cumulative meiotic and spermiogenic defects. PLoS One 6(10), e25241. 
Roush, S. and Slack, F. J. (2008). The let-7 family of microRNAs. Trends Cell Biol 18(10), 50516.

Russell, L.D., Ettlin, R.A., Hikim, A.P. and Clegg, E.D. (1990) Mammalian spermatogenesis Histological and histopathological evaluation of the testis: Cache River Press, Clearwater, FL. Shenoy, A. and Blelloch, R. H. (2014). Regulation of microRNA function in somatic stem cell proliferation and differentiation. Nat Rev Mol Cell Biol 15(9), 565-76.

Subramanian, A., Tamayo, P., Mootha, V. K., Mukherjee, S., Ebert, B. L., Gillette, M. A., Paulovich, A., Pomeroy, S. L., Golub, T. R., Lander, E. S. et al. (2005). Gene set enrichment analysis: a knowledge-based approach for interpreting genome-wide expression profiles. Proc Natl Acad Sci U S A 102(43), 15545-50.

Suzuki, A., Hirasaki, M., Hishida, T., Wu, J., Okamura, D., Ueda, A., Nishimoto, M., Nakachi, Y., Mizuno, Y., Okazaki, Y. et al. (2016). Loss of MAX results in meiotic entry in mouse embryonic and germline stem cells. Nat Commun 7, 11056.

Suzuki, A. and Saga, Y. (2008). Nanos2 suppresses meiosis and promotes male germ cell differentiation. Genes Dev 22(4), 430-5.

Wang, S., Wang, X., Ma, L., Lin, X., Zhang, D., Li, Z., Wu, Y., Zheng, C., Feng, X., Liao, S. et al. (2016). Retinoic Acid Is Sufficient for the In Vitro Induction of Mouse Spermatocytes. Stem Cell Reports 7(1), 80-94.

Wang, S., Wang, X., Wu, Y. and Han, C. (2015). IGF-1R signaling is essential for the proliferation of cultured mouse spermatogonial stem cells by promoting the G2/M progression of the cell cycle. Stem Cells Dev 24(4), 471-83.

Wu, Q., Song, R., Ortogero, N., Zheng, H., Evanoff, R., Small, C. L., Griswold, M. D., Namekawa, S. H., Royo, H., Turner, J. M. et al. (2012). The RNase III enzyme DROSHA is essential for microRNA production and spermatogenesis. J Biol Chem 287(30), 25173-90. Yoshida, S. (2019). Heterogeneous, dynamic, and stochastic nature of mammalian spermatogenic stem cells. Curr Top Dev Biol 135, 245-285.

Zhang, T., Murphy, M. W., Gearhart, M. D., Bardwell, V. J. and Zarkower, D. (2014). The mammalian Doublesex homolog DMRT6 coordinates the transition between mitotic and meiotic developmental programs during spermatogenesis. Development 141(19), 3662-71.

Zhang, T., Oatley, J., Bardwell, V. J. and Zarkower, D. (2016). DMRT1 Is Required for Mouse Spermatogonial Stem Cell Maintenance and Replenishment. PLoS Genet 12(9), e1006293.

Zhang, T. and Zarkower, D. (2017). DMRT proteins and coordination of mammalian spermatogenesis. Stem Cell Research 24, 195-202.

Zhou, Q., Li, Y., Nie, R., Friel, P., Mitchell, D., Evanoff, R. M., Pouchnik, D., Banasik, B., McCarrey, J. R., Small, C. et al. (2008). Expression of stimulated by retinoic acid gene 8 (Stra8) and maturation of murine gonocytes and spermatogonia induced by retinoic acid in vitro. Biol Reprod 78(3), 537-45.

Zimmermann, C., Romero, Y., Warnefors, M., Bilican, A., Borel, C., Smith, L. B., Kotaja, N., Kaessmann, H. and Nef, S. (2014). Germ cell-specific targeting of DICER or DGCR8 reveals a novel role for endo-siRNAs in the progression of mammalian spermatogenesis and male fertility. PLoS One 9(9), e107023. 


\section{Figures}

A

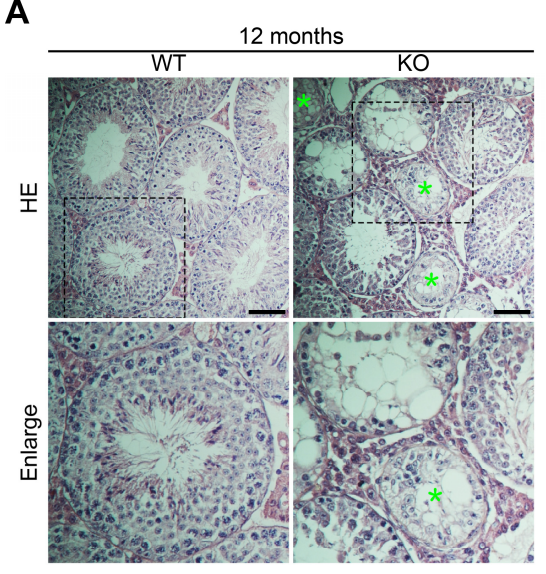

C

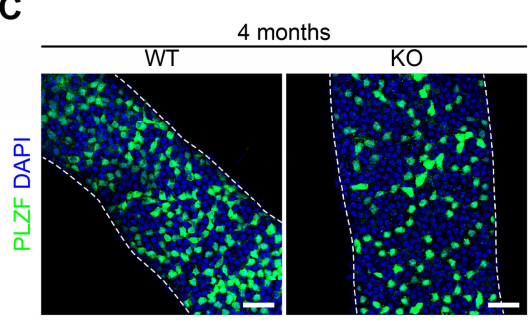

G

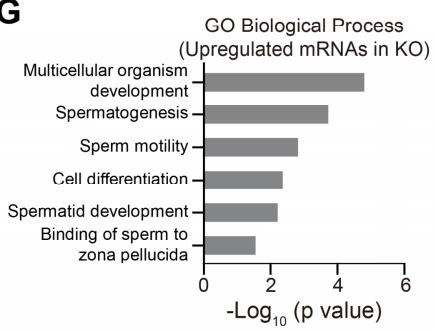

B
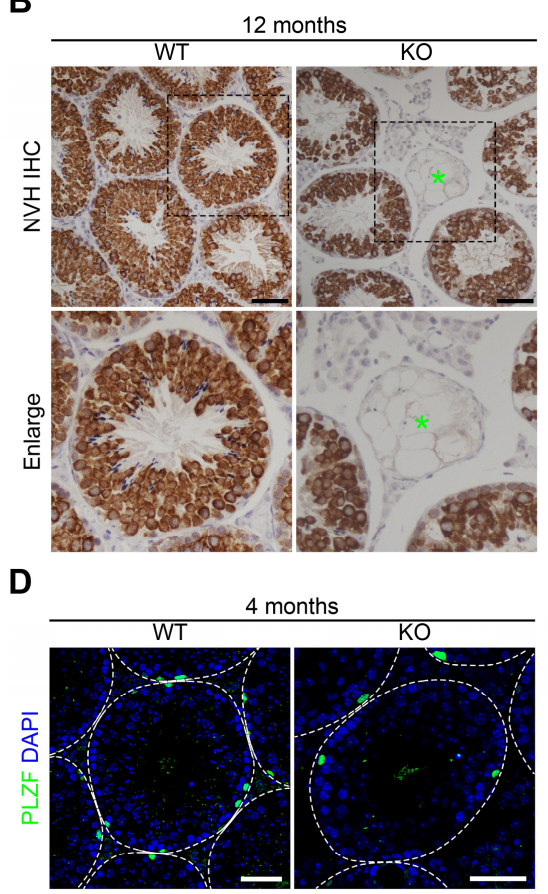

H

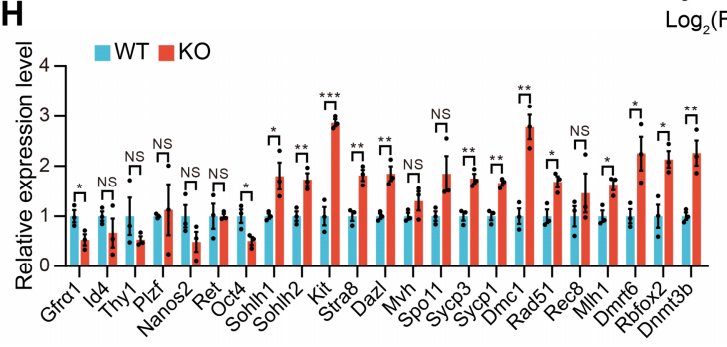

E

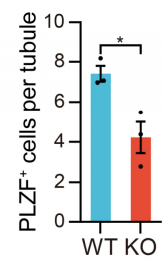

F Down ••Up

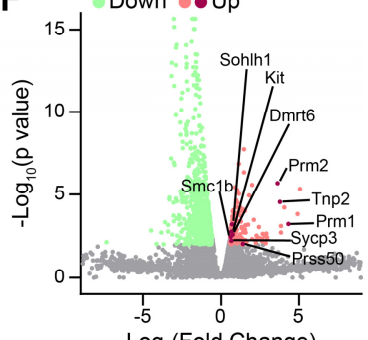

$g_{2}$ (Fold Change)

Fig. 1. miR-202 knockout reduces the undifferentiated spermatogonial pool. (A)

Histological analysis of testis sections from WT and KO mice by H\&E staining at 12 months of age. Magnified views are indicated by dashed areas. Green asterisks indicate the agametic tubules. (B) Immunohistochemistry of the germ cell marker MVH in testicular sections from mice at 12 months of age. Magnified views are indicated by dashed areas. Green asterisks indicate the agametic tubules. (C and D) Immunofluorescent staining for PLZF in whole-mount tubules (C) or sections (D) from WT and KO mice at four months of age. Dotted white line, outline of seminiferous tubules or testis tubules. (E) Average numbers of PLZF-positive cells per tubule in (D). At least 50 tubules were counted for each mouse. (F) Volcano plots showing differentially expressed genes between WT and KO SG-A. Upregulated genes are indicated by red dots and downregulated genes are indicated by green dots. (G) Representative Gene Ontology (GO) terms of the biological process categories enriched in upregulated mRNAs in KO SG-A, as identified by RNA-seq. (H) qPCR 
bioRxiv preprint doi: https://doi.org/10.1101/2021.06.27.449895; this version posted June 28, 2021. The copyright holder for this preprint

(which was not certified by peer review) is the author/funder, who has granted bioRxiv a license to display the preprint in perpetuity. It is made available under aCC-BY-NC-ND 4.0 International license.

analysis of gene expression in WT and KO SG-A. Data are normalized to WT SG-A.

All panels show mean \pm SEM, ${ }^{*} \mathrm{p}<0.05,{ }^{*} \mathrm{p}<0.01,{ }^{* * *} \mathrm{p}<0.001$. NS, not significant. Scale bars, $50 \mu \mathrm{m}$. 
A
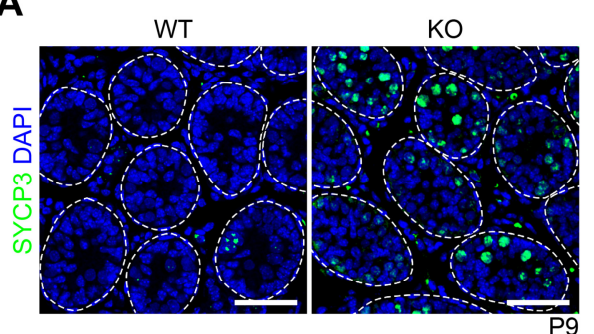

B
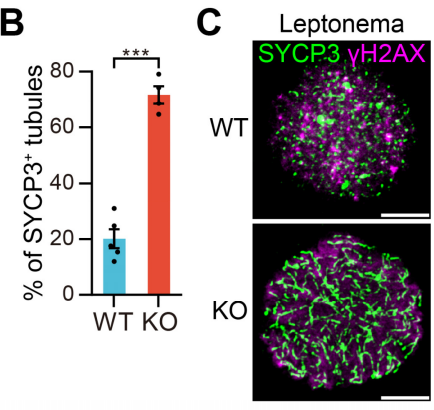

$\mathbf{F}$
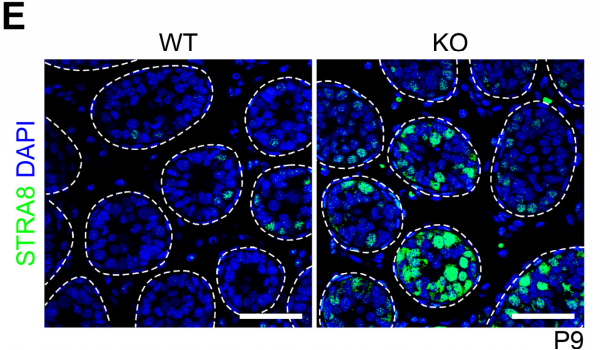

G

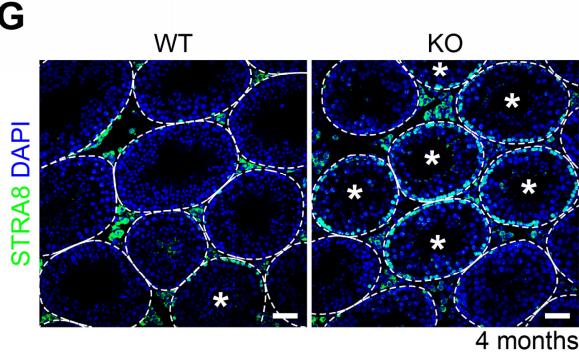

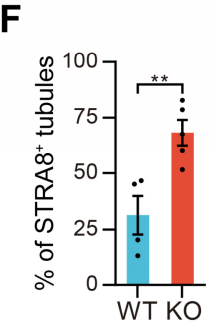

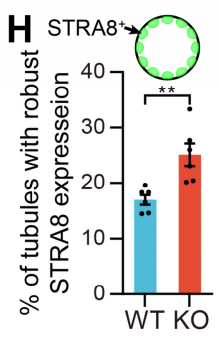

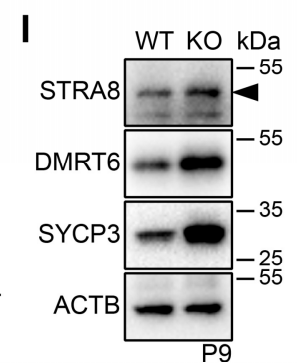

K

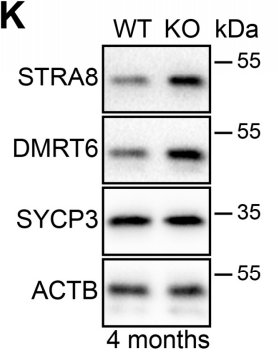

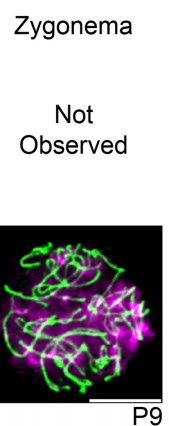
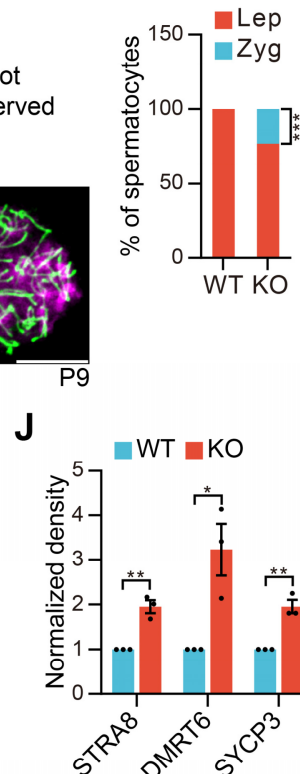

$\mathbf{L}$

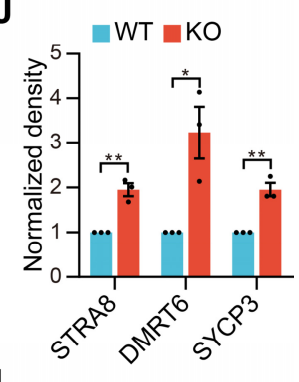

L $\square$ WT $\square$ KO

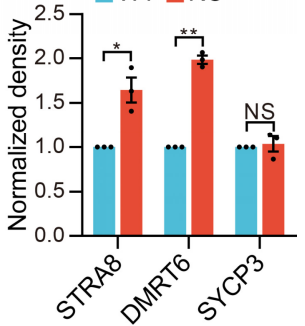

Fig. 2. miR-202 knockout induces precocious meiotic initiation. (A)

Immunofluorescent staining for SYCP3 in histological sections from mice at P9.

Dotted white line, outline of testis tubules. (B) Proportion of tubules containing

$\mathrm{SYCP}^{+}$cells in (A). At least 50 tubules were counted for each mouse. (C)

Immunofluorescent staining for SYCP3 and $\gamma \mathrm{H} 2 \mathrm{AX}$ in nuclear spreads of spermatocytes from mice at P9. (D) Proportion of leptonema and zygonema in (C). $n$ = 3. $(\mathbf{E}$ and $\mathbf{G})$ Immunofluorescent staining for STRA8 in sections from mice at P9

(E) and 4 months of age $(\mathrm{G})$. White asterisks indicate tubules with robust STRA8 expression in (G). Dotted white line, outline of testis tubules. (F and $\mathbf{H})$ Proportion of tubules containing STRA8- positive cells at P9 (F) and tubules with robust STRA8 expression at 4 months of age $(\mathrm{H})$. The upper panel in $(\mathrm{H})$ is the schematic representation for robust STRA8 expression. At least 50 tubules were counted for each mouse. (I and $\mathbf{K}$ ) Western blotting analyses of WT and KO testes from mice at P9 (I) and 4 months of age (K), $n=3$. ( $\mathbf{J}$ and $\mathbf{L})$ The normalized densities in (I) and $(\mathrm{K})$, respectively. All panels show mean $\pm \mathrm{SEM},{ }^{*} \mathrm{p}<0.05, * * \mathrm{p}<0.01, * * * \mathrm{p}<0.001$. NS, not significant. Scale bars, $50 \mu \mathrm{m}$. 
A
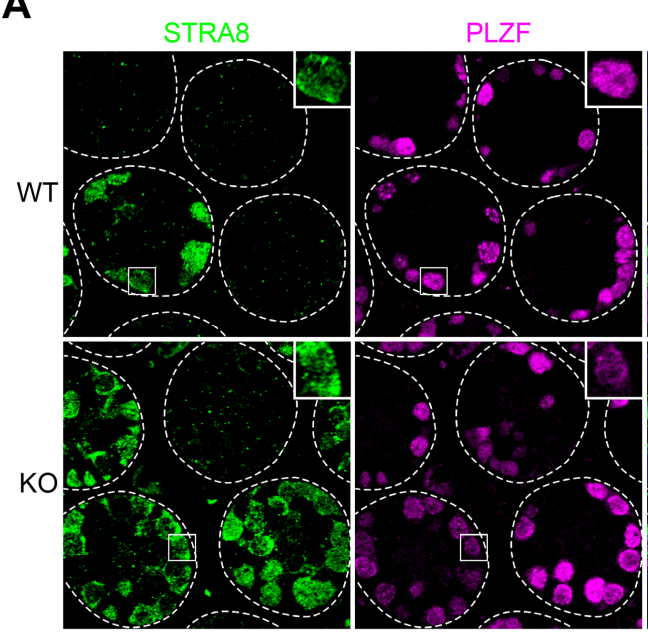

STRA8 PLZF DAPI
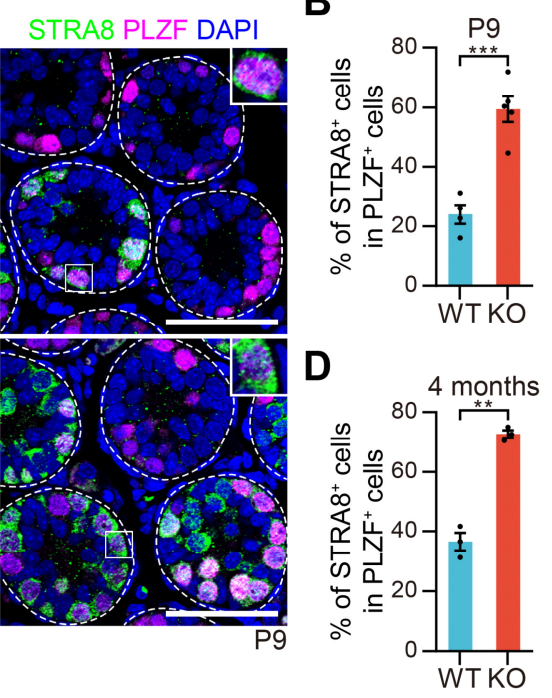

C

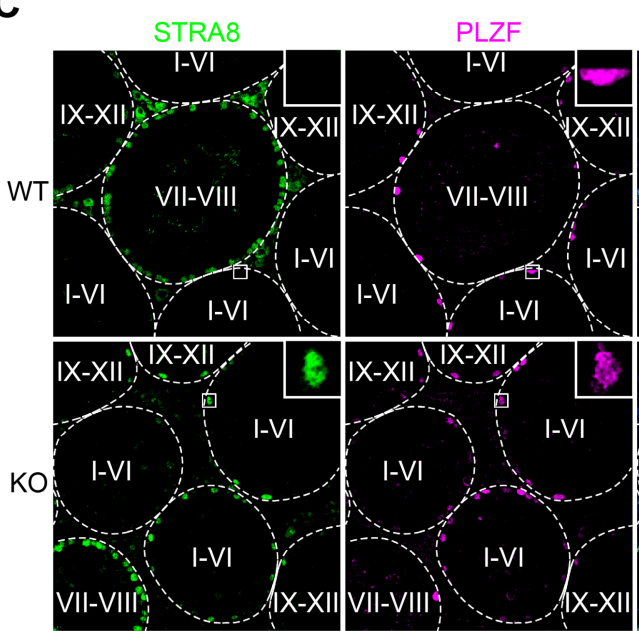

STRA8 PLZF DAPI

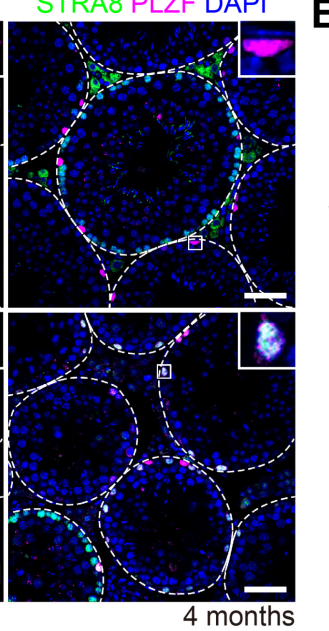

E

OSTRA8 expression in WT

Addtional STRA8 expression in KO

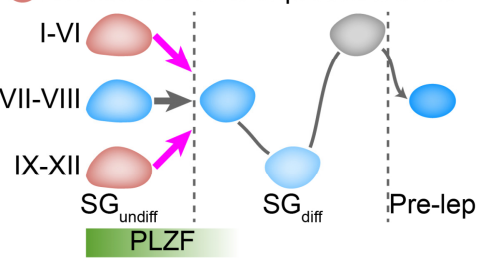

Fig. 3. miR-202 knockout induces early and widespread presence of STRA8 in

undifferentiated spermatogonia. (A and C) Immunofluorescent staining for STRA8 and PLZF in sections from mice at P9 (A) and 4 months of age (C). Insets show highmagnification images of boxed regions. The seminiferous tubules in adult sections (C) were classified into three types based on their seminiferous stages. Dotted white line, outline of testis tubules. (B and D) The percentage of STRA $8^{+}$cells in PLZF ${ }^{+}$ undifferentiated spermatogonia in (A) and (C), respectively. At least 50 tubules were counted for each mouse. (E) Diagram of STRA8 expression in SG $_{\text {undiff, }} \mathrm{SG}_{\text {diff }}$ and preleptonema, in WT (blue) and KO (blue + pink) mice. Magenta arrows indicate the uncontrolled transition from undifferentiated to differentiating spermatogonia in KO. Diagram is based on observations in (C). All panels show mean $\pm \mathrm{SEM},{ }^{* *} \mathrm{p}<0.01$, $* * * \mathrm{p}<0.001$. NS, not significant. Scale bars, $50 \mu \mathrm{m}$. 
A

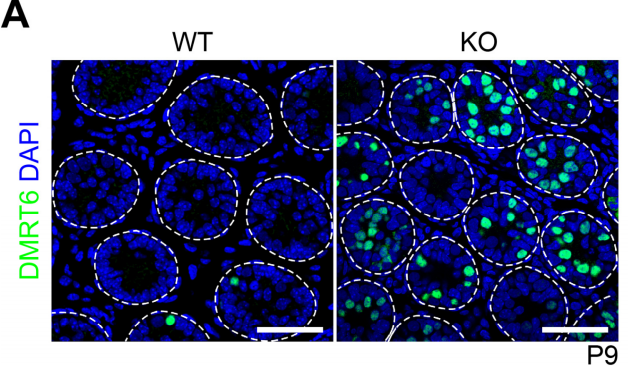

c

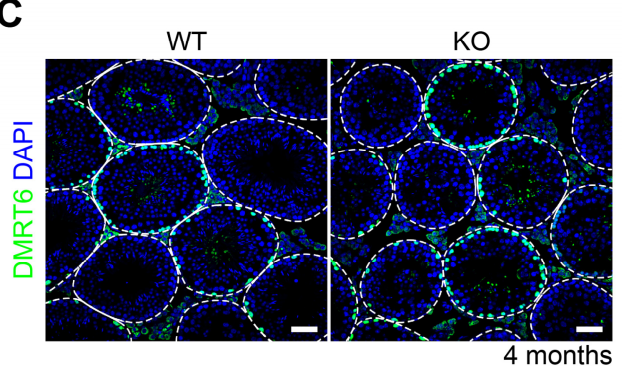

B

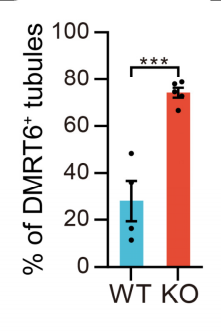

D

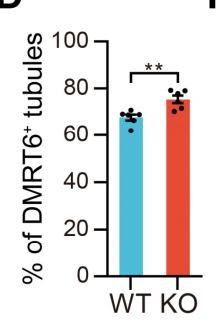

E

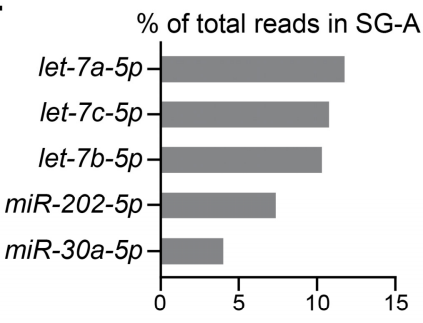

$\mathbf{F}$

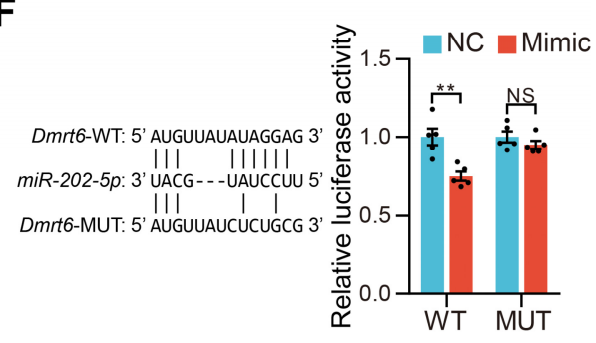

Fig. 4. miR-202 knockout leads to DMRT6 pre-activation. (A and C)

Immunofluorescent staining for DMRT6 in sections from mice at P9 (A) and 4 months of age (C). Dotted white line, outline of testis tubules. (B and D) Proportion of tubules containing DMRT6-positive cells at P9 (B) and 4 months of age (D). At least 50 tubules were counted for each mouse. (E) Percentage of total reads for the five most abundant miRNAs in SG-A. Note that $m i R-202-5 p$ occupies $\sim 7 \%$ of total reads. (F) Validation of Dmrt6 mRNA as a direct target of $m i R-202-5 p$ by dual luciferase assay. Data are normalized to the scrambled negative control (NC) mimic. Left panel, the sequence of $m i R-202-5 p$, and predicted miRNA regulatory elements at the 3' UTR of Dmrt6 mRNA and mutated 3' UTR sequence. All panels show mean $\pm \mathrm{SEM},{ }^{* *} \mathrm{p}<$ $0.01, * * * p<0.001$. NS, not significant. Scale bars, $50 \mu \mathrm{m}$. 
A
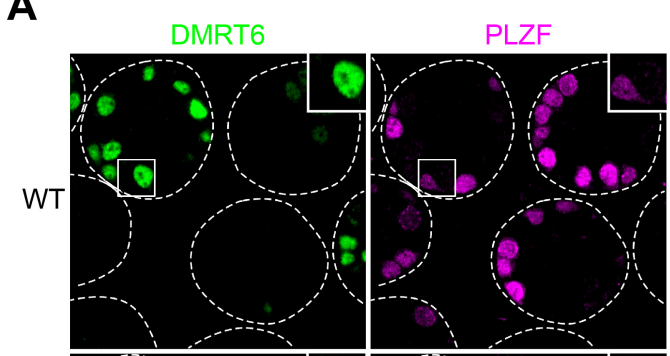

DMRT6 PLZF DAPI
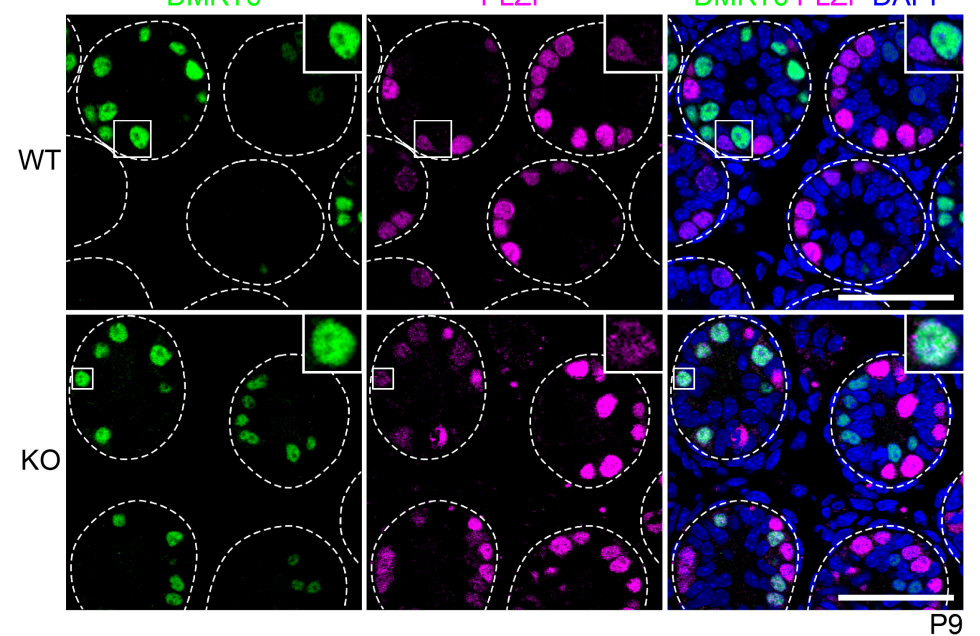

B

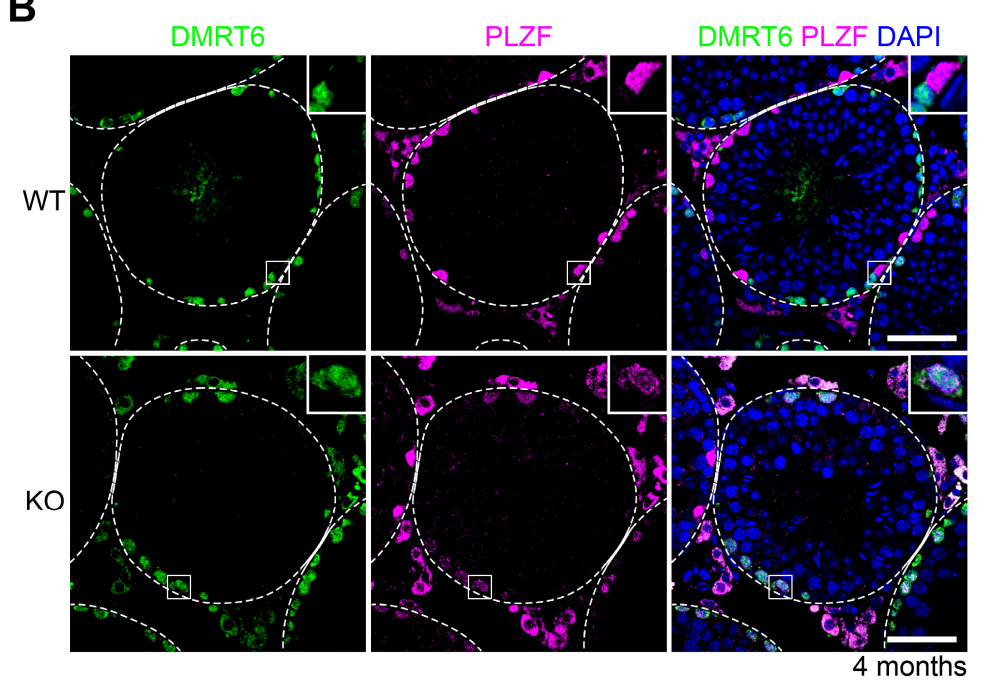

Fig. 5. $m i R-202$ knockout induces precocious expression of DMRT6 as early as in

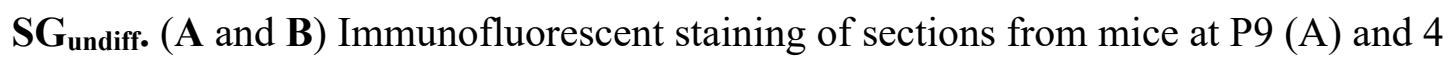
months of age (B) for DMRT6 and PLZF. Insets show high magnification images of boxed regions. Dotted white line, outline of testis tubules. Scale bars, $50 \mu \mathrm{m}$. 

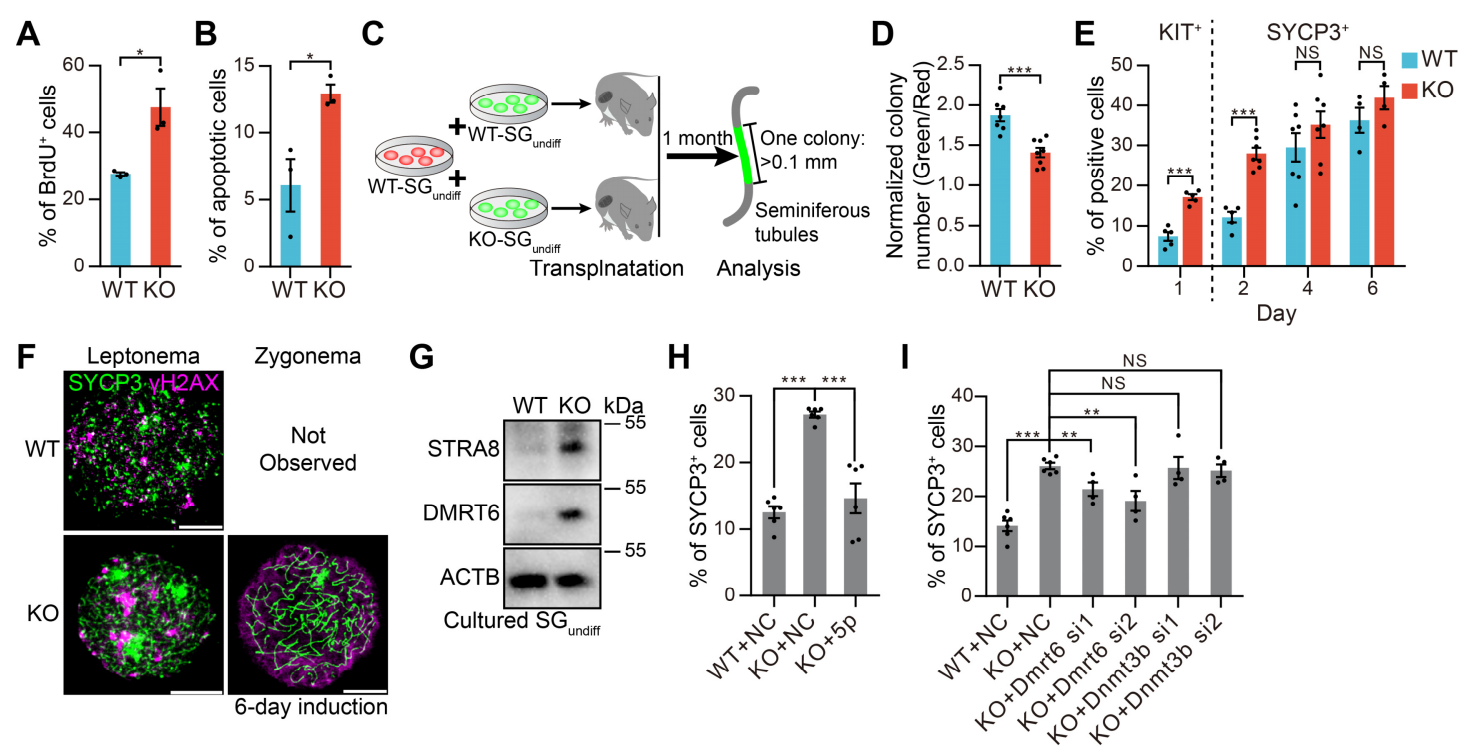

Fig. 6. miR-202 knockout primes undifferentiated spermatogonia for

\section{differentiation and meiotic initiation. (A and B) Proportion of $\mathrm{BrdU}^{+}(\mathrm{A})$ and}

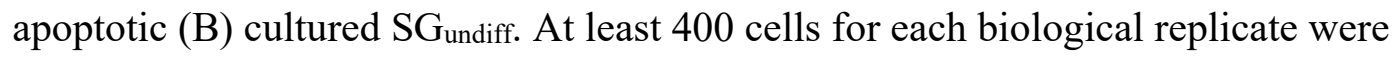
counted. (C) Scheme of transplantation assay. EGFP-labelled WT or KO cultured

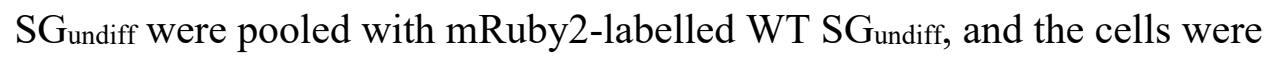
transplanted into recipient mice. One month later, colony number was counted. (D) Quantitative comparison of stem cell content of WT and KO SGundiff by transplantation assay in (C). Note that mRuby2-labelled SGundiff were used as internal controls. (E) Proportion statistics of KIT- and SYCP3-positive cells in WT and KO $\mathrm{SG}_{\text {undiff }}$ by flow cytometric analyses after meiotic induction on Sertoli cells for the indicated time. (F) Nuclear spread staining of WT and KO SGundiff for SYCP3 and $\gamma \mathrm{H} 2 \mathrm{AX}$ after induction on Sertoli cells for 6 days. $\mathrm{n}=3$. (G) Western blotting analyses in cultured $\mathbf{S G}_{\text {undiff, }} \mathrm{n}=3$. (H and I) Proportion statistics of SYCP3-positive cells in WT and KO SG undiff by flow cytometric analyses after pretreatment with mimics (H) or siRNAs (I) for 10 hours and induction on Sertoli cells for two days. All panels show mean \pm SEM, ${ }^{*} \mathrm{p}<0.05, * * \mathrm{p}<0.01, * * * \mathrm{p}<0.001$. NS, not significant. Scale bars, $10 \mu \mathrm{m}$. 
A

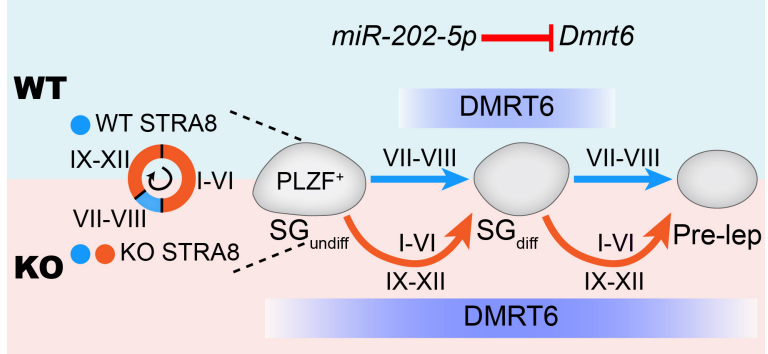

B
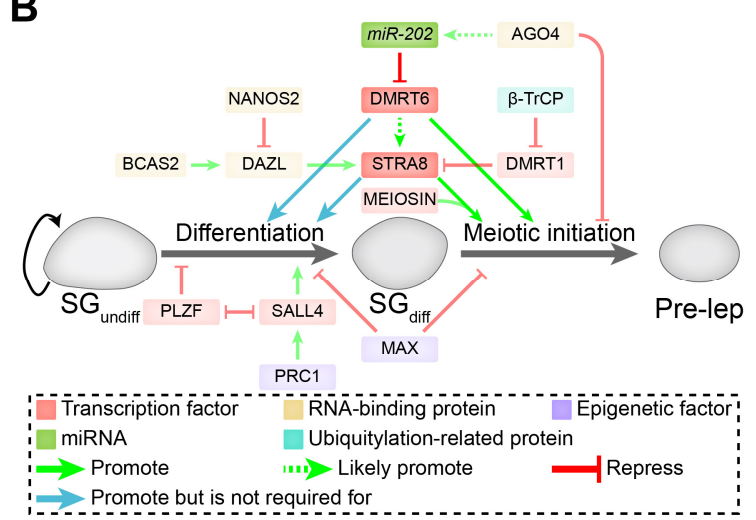

Fig. 7. miR-202, DMRT6 and STRA8 act together as a novel module in the regulatory network of spermatogonial differentiation and meiotic initiation. (A)

MiR-202 prevents precocious spermatogonial differentiation and meiotic initiation. In WT mice, $m i R-202$ directly targets Dmrt6 mRNA and restricts the expression window

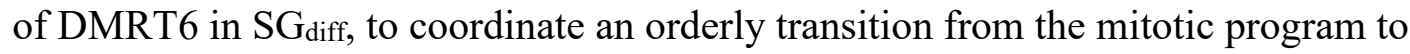
the meiotic program. The transitions of spermatogonial differentiation and meiotic initiation cooccur in stages VII-VIII, with expression of STRA8. Upon miR-202 KO, DMRT6 is precociously expressed as early as in $\mathrm{SG}_{\text {undiff, causing precocious }}$ spermatogonial differentiation and meiotic initiation, and a reduced $\mathrm{SG}_{\text {undiff }}$ pool, with the presence of STRA8 in all stages in SGundiff. (B) The regulatory network composed of miR-202, DMRT6, STRA8 and other regulators orchestrates spermatogonial differentiation and meiotic initiation. 